\title{
CUMBRES IBEROAMERICANAS: RESILIENCIA Y RELEVANCIA TRES DÉCADAS DESPUÉS
}

\author{
Luis G. Solís Rivera \\ 14 de julio de 2021
}

\section{Introducción}

La decisión de los jefes de Estado y de Gobierno de Iberoamérica, reunidos en México en 1991, de instituir las Cumbres anuales de esta comunidad, fue visionaria. Acogiendo las raíces culturales y lo que llamaron "un rico patrimonio (fundado) en la suma de los pueblos, credos y sangres diversos" como ejes articuladores de esta comunidad peculiar $-\mathrm{y}$ no la geopolítica-, decidieron construirla como un "espacio común" capaz de reconocerse unido aun en esa diversidad. La decisión fue también propia del contexto en que se produjo. Acababa de concluir la Guerra Fría y el concepto de Estadonación no vivía sus mejores días. Aunque las grietas en los Balcanes ya se habían abierto irrevocablemente, y pese a que el mundo caminaba hacia los horrores del terrorismo fundamentalista, aún prevalecía en Occidente una hermosa presunción democrática. En efecto, en la Europa atlántica sólidamente integrada, y en una América Latina crecientemente unida por el ideal de la libertad con pluralismo, la ilusión de concretar definitivamente la que hasta entonces había sido una democracia elusiva y difuminada se veía al alcance de la mano.

En el decir de los presidentes asistentes a la Cumbre de Guadalajara:

Al final del siglo XX se configura el surgimiento de un nuevo esquema de organización de las relaciones internacionales. (...) Solo una sociedad internacional regida por el Derecho puede asegurar la paz y la seguridad para todos los pueblos. En esa tarea deberá desempeñar un papel esencial la Organización de las Naciones Unidas, unas Naciones Unidas revitalizadas y renovadas y a las que la nueva situación internacional debe facilitar la consecución efectiva de los fines para los que fueron creadas. El fortalecimiento de las bases de convivencia y justicia internacionales conforme a los principios y propósitos de la Carta de las Naciones Unidas es una responsabilidad compartida por todos los Estados y no una prerrogativa exclusiva de algunos. Se trata de un proceso que debe ser abierto y participativo, en el cual se hagan valer los intereses de la comunidad internacional en su conjunto (Guadalajara 1991, núm. 19-20).

Todos los presidentes y jefes de Estado y Gobierno participantes en la primera Cumbre de Guadalajara, con excepción de Fidel Castro y - por su condición de monarca- el rey de España, representaban en ese momento fundacional, como colectivo, 
la primera generación de mandatarios democráticamente electos de las Américas. Y lo habían conseguido (este no es un tema menor), ya fuera ganando elecciones libres, y hasta donde se supo, limpias, o bien tras hermosas jornadas cívicas en que, desde la calle, sus pueblos lograron imponerse a regímenes que se aferraban tercamente al poder desde hacía décadas. Hubo en aquello, por lo tanto, mucho de legitimidad popular y hasta algo de heroísmo cívico.

No es de extrañar, por lo tanto, que la Declaración de Guadalajara manifestara con toda claridad:

Reconocemos que este propósito de convergencia se sustenta no solo en un acervo cultural común sino, asimismo, en la riqueza de nuestros orígenes y de su expresión plural. Nuestra comunidad se asienta en la democracia, el respeto a los derechos humanos y en las libertades fundamentales. En este marco, se reafirman los principios de soberanía y de no intervención y se reconoce el derecho de cada pueblo a construir libremente en la paz, estabilidad y justicia, su sistema político y sus instituciones (Guadalajara, 1991, núm. 3).

Evidentemente no todo eran ilusiones sobre la perdurabilidad de aquella bocanada de aire fresco que, iniciada en la Conferencia de Malta entre Reagan y Gorbachov (1985) y continuada en Centroamérica con la firma de los Acuerdos de Paz de Esquipulas II (1987), trajo consigo la auspiciosa caída del Muro de Berlín (1989) y, con ella, la disolución del bloque soviético y el fin de la Guerra Fría a partir de esa fecha.
En ese marco se revivieron los debates en torno a la capacidad de la democracia, como modelo político y forma de vida, de arraigarse, crecer y fructificar en contextos culturales no occidentales. Planteado por primera vez por Max Weber y retomado después por la escuela "tradicionalista" en EE.UU., el tema se revivió con las tesis de Samuel Huntington y su propuesta sobre el "choque de civilizaciones”. Ello se complicó aún más cuando entraron en el debate los conceptos de "gobernabilidad" y "gobernanza", que vinieron de la mano de otros que buscaban sustituir las viejas definiciones de la llamada "democracia formal o democracia electoral": el "desarrollo humano" y la "seguridad democrática".

Pero lo cierto es que — dudas más, dudas menos-, imperaba en aquellos días una cierta euforia política en torno a las posibilidades de avanzar sin el lastre de la fenecida Guerra Fría, un fenómeno que atosigó a más de dos generaciones y colocó al mundo a las puertas del holocausto atómico. Fue precisamente esa ensoñación la que inspiró e hizo posible la creación, y posteriormente la consolidación, de las Cumbres Iberoamericanas. Ello sería posible, entre otros factores, gracias a un poderoso llamado a promover la cooperación entre los países miembros. Una cooperación definida como un “(...) instrumento de solidaridad y vínculo político, económico, social y cultural que contribuye a fortalecer el senti- 
miento de identidad y pertenencia a la Comunidad Iberoamericana" (Bávaro, 2002, núm. 46)

Navegar las procelosas aguas iberoamericanas

Sin duda la década de los años 1990 fue una de grandes expectativas en el mundo iberoamericano. En el entorno europeo, no obstante, aquellos años también fueron de profundos dolores por los acontecimientos producidos por la desintegración de la antigua Yugoslavia (1991-2001). España y Portugal no pudieron sino verse afectados por ellos. Los efectos de la crisis en el Este europeo, así como los ajustes que traerían aparejados las transiciones democráticas en las exrepúblicas comunistas (especialmente en Alemania) llevaron las tensiones al máximo en el interior de la Unión Europea (UE). Pero también la consolidaron. Una muestra de ello fue la suscripción del Tratado de Maastricht el 7 de julio de 1992. Y esa consolidación, que tuvo como telón de fondo las terribles matanzas en Bosnia y Kosovo, así como las transiciones democráticas en Centroeuropa, trajo consigo un renovado propósito integrador que en aquel momento pareció imbatible.

A ese respecto, la visión de las y los mandatarios iberoamericanos fue clara desde la Declaración de Cartagena de Indias (1994), reiterada en Oporto (1998); especialmente en esta última: los procesos de integración existentes en América Latina y Eu- ropa, en los cuales participan los países iberoamericanos, son "complementarios", siendo un objetivo fundamental de la comunidad iberoamericana hacerlos converger. Ello, sin sustituirlos y procurando estrechar cada vez más las relaciones entre sí. Así quedó definitivamente acordado cuando las Cumbres asumieron un papel protagónico en la Asociación Estratégica Birregional surgida de la I Cumbre UE-América Latina y el Caribe (Rio de Janeiro, junio de 1999).

Del otro lado del Atlántico, en América Latina y el Caribe, el último decenio del siglo XX se inició en una nota optimista. Alentada por un importante repunte económico y, sobre todo, por el surgimiento de un cierto espíritu autonomista - tras la invasión de Panamá en 1989 y el hundimiento pocos años después del Área de Libre Comercio de las Américas (ALCA)—, en la región se produjo el reavivamiento de instancias regionales y subregionales de concertación y diálogo político. Instancias que, como la propia comunidad iberoamericana, buscaban establecer espacios propios, respetuosos de la especificidad cultural, sin la participación de EE.UU. y al margen de las tradicionales "instancias interamericanas" encabezadas por la Organización de Estados Americanos (OEA) y sus instituciones especializadas. Las iniciativas más importantes de ese periodo fueron, además de la Comunidad Iberoamericana de Naciones, 
indudablemente la creación del Grupo de Río, heredero del Grupo de Contadora y su Grupo de Apoyo (1991), así como del Mercosur, que surgió ese mismo año.

En el plano subregional también se produjeron avances. Centroamérica refundó su Mercado Común, convertido en el Sistema de la Integración Centroamericana (SICA), por medio del Protocolo de Tegucigalpa (1991), y se reactivaron las acciones del Pacto Andino. Tres años después, en 1994, se fundó la Asociación de Estados del Caribe, la cual, por primera vez de manera formal, concretó la vieja aspiración de contar con un foro que integrase a las naciones insulares y continentales de la Cuenca del Caribe (incluyendo, por lo tanto, a México, Colombia y Venezuela). También en 1994 Centroamérica suscribió la Alianza para el Desarro1lo Sostenible (ALIDES), el primer instrumento derivado de los Acuerdos de la Conferencia de Río (1992), que fue la base de notables avances como la promulgación del Tratado Centroamericano de Seguridad Democrática y el Tratado de Integración Social, ambos de 1995.

No obstante, el auspicioso desarrollo multilateral experimentado en el primer quinquenio de esa década fue perdiendo su impulso a medida que las aguas del cambio motivado por el fin de la Guerra Fría volvieron a sus cauces. En Colombia arreció el conflicto armado interno, agravado aho- ra por el terrorismo de los cárteles del narcotráfico. En Venezuela, el fallido intento de golpe de Estado contra el presidente Carlos Andrés Pérez, encabezado por un entonces desconocido militar llamado Hugo Chávez (1992), desató una crisis política que llevaría al país pocos años después por sendas insospechadas en aquel momento. En Perú, las guerrillas de Sendero Luminoso, muy afectadas por la captura de su comandante Abimael Guzmán en 1992, continuaron sus acciones terroristas hasta entrado el año 2000. También lo hizo el Movimiento Revolucionario Tupac Amaru (MRTA), cuya toma de la embajada de Japón en Lima (1996) terminó en una matanza que propulsó la autoritaria $-\mathrm{y}$ posteriormente corrupta - gestión del entonces presidente Alberto Fujimori. En México, se produjo la sorpresiva aparición del Movimiento Zapatista de Liberación Nacional en Chiapas (1994). Mientras tanto, Centroamérica vio su promisoria perspectiva de progreso humano malograda por los impactos del huracán Mitch, que asoló Honduras, Nicaragua y Guatemala (1998), pero además ralentizó hasta casi paralizar los esfuerzos de concertación regional del SICA que se habían multiplicado significativamente desde 1994.

Así, el cambio de marcha que se produce en el mundo a partir de 1995 es notorio. Las tendencias positivas hacia el multilateralismo y la integración perdieron fuerza y se inició 
un período que estará dominado por tres procesos concomitantes en el mundo. En primer lugar, el advenimiento del terrorismo islamista con sus terribles impactos en las sociedades estadounidense y europeas, cuyos ejemplos más emblemáticos son los ataques a las Torres Gemelas en Nueva York (2001), los trenes de cercanías de Madrid (2004), el metro de Tokio y la línea de autobuses de Londres (2005). Este fenómeno traerá consigo la extensión de la guerra durante dos décadas, desde el Este de Europa hasta Irak, Afganistán y finalmente Siria, e involucrará de manera especialmente compleja a España y Portugal, países miembros de la OTAN, pero que también se sumaron a la llamada "Coalición de la Voluntad" convocada por EE.UU. para invadir Irak sin contar con la autorización del Consejo de Seguridad de las Naciones Unidas (2003). Un segundo factor que se desató en esta década es el euroescepticismo, cuya expresión más clara fue el rechazo al proyecto de Constitución europea en Francia y los Países Bajos. Y finalmente, las crisis económicas y financieras que culminaron con la gran recesión de 2008, cuyo impacto fue brutal en el mundo.

Desde 1992 las Cumbres se pronunciaron en cuatro ocasiones contra el terrorismo, por medio de declaraciones especiales y, en una, nombrando específicamente a ETA, que no contó con el apoyo de Cuba. En ese sentido, no hubo omisión en un asunto que dominaría más de una década la agenda mundial. Y ello, en términos inequívocos:

(...) reforzaremos nuestras legislaciones nacionales y promoveremos una cooperación internacional activa y eficaz para prevenir, reprimir y eliminar toda manifestación de este flagelo. Asimismo, nos comprometemos a tomar medidas para prevenir y eliminar el financiamiento y la preparación de cualquier acto terrorista y a negarle refugio a los instigadores, financiadores, autores, promotores o participantes en actividades terroristas (...) (Salamanca, 2005, Comunicado Especial).

También se acogió en el seno de las Cumbres, por iniciativa de Argentina, un concepto propuesto por España para evitar que la lucha armada contra la amenaza terrorista terminara en una "cruzada": la llamada "Alianza de Civilizaciones". Esta Alianza ya se había perfilado en la Cumbre de Lima (2001), como:

(...) un diálogo entre civilizaciones y el respeto a la diversidad cultural, étnica, religiosa y racial, como una forma de contribuir a una convivencia basada en el respeto y la promoción de una cultura de paz (Declaración política contra el terrorismo).

Sin embargo, no fue sino hasta la XIV Cumbre de San José de Costa Rica (2004) que se produjo un apoyo expreso a esta iniciativa que, ya entonces, se había colocado en la agenda de la Asamblea General de las Naciones Unidas.

Pocos años después, la región latinoamericana y caribeña se enrumbará por una senda muy escabrosa que terminará descalabrando casi todos 
los mecanismos de diálogo político del Hemisferio. Marcada por la creciente polarización entre gobiernos conservadores y otros a los que se denominará, con diversos matices e intensidad, "populistas" o "socialistas del siglo XXI", los países de la región se enfrentarán en casi todos los temas de la agenda regional y global. Pese a ello, en lo relativo a las Cumbres Iberoamericanas, estas no se vieron escindidas por las discrepancias ideológicas que tensaron $\mathrm{y}$, en última instancia, pusieron fin, a muchos de los espacios multilaterales de diálogo político en las Américas. A lo sumo experimentaron tensiones pasajeras, entre las cuales la única que generó algún grado de interés (y ello por su naturaleza anecdótica, más que política) fue la producida por la ya muy conocida frase del rey de España dirigida al presidente venezolano Hugo Chávez: “¿Por qué no te callas?" (Santiago de Chile, 2007)

De hecho, contrario a lo que ocurrió en otros organismos multilaterales regionales y universales, las Cumbres Iberoamericanas se pronunciaron reiterada y contundentemente sobre la necesidad de defender la democracia, un tema que en sí mismo produjo algunos de los mayores enfrentamientos entre los gobiernos de la región, en especial tras la muerte de Hugo Chávez en 2013 y la progresiva evolución autoritaria de los gobiernos de ese país, y de Nicara- gua, Bolivia, Ecuador y, en menor medida, Argentina.

En este sentido, la Comunidad Iberoamericana de Naciones avaló al sistema democrático desde sus inicios, y mantuvo desde entonces una posición que prácticamente se ha mantenido incólume:

Reafirmamos nuestro compromiso de promover y defender la democracia y el Estado de derecho, el pluralismo político y la identidad cultural... En el común propósito de fortalecer el sistema democrático así como asegurar la gobernabilidad democrática, apoyando acciones que consoliden una cultura democrática y el Estado de derecho, que se sustentan en la libertad, la paz, la tolerancia y la participación social y ciudadana y la justicia social (...) (Bávaro, 2002, núm. 3).

Pero también las Cumbres se han pronunciado sobre una gran cantidad de asuntos medulares de la agenda global que, aun hoy polémicos debido a la alta polarización del discurso político, fueron asumidos de manera bastante sistemática a lo largo de más de 25 años, sin que ello llegara a hacerlas naufragar. Es decir, mientras que el mundo de la pos-Guerra Fría entraba en una etapa de crispación creciente, de parálisis de las instituciones regionales y de tendencias antiglobalizadoras, la comunidad iberoamericana y sus Cumbres continuaban funcionando, pese a los serios enfrentamientos entre los gobiernos de sus Estados miembros en otros foros similares y a propósito de temas idénticos. Sobresalen a este respecto las deliberaciones que se han realizado en torno a la educa- 
ción, la cooperación para el desarrollo, la inclusión social, las migraciones, la innovación y el conocimiento, las juventudes y el desarrollo, la transformación del Estado y las políticas para la sostenibilidad, siendo estas últimas (y de manera más particular, las cuestiones relativas al ambiente) parte integral de las reflexiones de las Cumbres desde casi el momento mismo de su fundación.

Cabe preguntarse entonces, ¿por qué espacios de diálogo político tan potentes como el Grupo de Río, la UNASUR, el Mercosur y, más recientemente, la Comunidad de Estados Latinoamericanos y Caribeños (CELAC, creada en 2011), se han visto paralizados o para todos los efectos desarticulados — debido a las profundas discrepancias ideológicas y políticas de sus miembros-, mientras que las Cumbres Iberoamericanas, teniendo una idéntica o casi idéntica membresía, no han experimentado una problemática similar? ¿Por qué mientras los países del llamado "bloque ALBA" (creado en 2004) han evidenciado profundas contradicciones con quienes no lo integran - llegando incluso a momentos de enfrentamiento militar, como el suscitado en 2008 entre Ecuador y Colombia-, esta conflictividad no ha tenido un correlato en el proceso de Cumbres Iberoamericanas? ¿Por qué rompe relaciones Venezuela con Colombia en 2019, pero no deja de relacionarse con ella en el marco comunitario iberoameri- cano? ¿Cuál es la razón de que el ALBA sostenga un enfrentamiento diplomático duro y de alto perfil en la OEA con el llamado Grupo de Lima (un enfrentamiento que involucra en los peores términos al propio secretario general de esa Organización, Luis Almagro), mientras mantiene relaciones normales en el marco de las Cumbres Iberoamericanas y recibe con beneplácito las gestiones de la secretaria general iberoamericana, Rebeca Grynspan?

\section{La resiliencia de las Cumbres Ibe- roamericanas}

No es sencillo encontrar respuestas a estas preguntas y otras que de ellas podrían derivarse. A continuación, se exploran algunas posibilidades, ninguna de las cuales, dicho sea de paso, basta individualmente para explicar este fenómeno, el cual es multicausal, y ha concedido a las Cumbres una preeminencia singular en el sistema internacional de nuestro tiempo.

Quizá la más obvia explicación radique, como ya se indicó, en la naturaleza "no geopolítica" de las Cumbres Iberoamericanas. Es decir, en que la lógica de su existencia radica en torno a la idea de una comunidad de identidades culturales compartidas, cuya racionalidad no se deriva de factores de dominación y hegemonía, sino de afinidades lingüísticas que se miran en perspectiva amplia. De ser así, existiría una suerte de "espíritu 
iberoamericano" que ha sido capaz de sobreponerse a otros factores "duros" de la realidad política de las últimas tres décadas. Pese a ello, en la práctica, las Cumbres se han pronunciado de manera contundente y abundante sobre el conjunto de desafíos mayores -estructurales tanto como coyunturales - que ha afectado al mundo a partir de su fundación en 1991. En ese sentido, no ha habido ni omisión ni timidez en las Cumbres y, por lo tanto, podrían haberse producido igualmente en su interior enfrentamientos que experimentaron otras instancias similares.

Otra explicación de la resiliencia de las Cumbre Iberoamericanas a las discrepancias que enfrentaron otras de formato parecido podría basarse en la redacción y contenido de sus declaraciones, las cuales denotan al menos tres características notables.

La primera es su consistencia. A lo largo de las últimas tres décadas, las declaraciones de los jefes y jefas de Estado y de Gobierno de la comunidad iberoamericana han sido coherentes, a pesar de contar posiciones discrepantes de fondo en muchos asuntos. Más allá de las materias específicas priorizadas en cada una de ellas, el marco valórico y de principios no ha sufrido desmedro. La segunda es su relevancia. En cada una de las Cumbres, la voz de los altos representantes iberoamericanos se recogió en declaraciones relativas a los principales aspectos de la agen- da mundial y su relación con la iberoamericana. Por esa razón resulta imposible concluir que las Cumbres Iberoamericanas sean reuniones geopolíticamente irrelevantes. Por el contrario, reflejan una voluntad comunitaria de tomar posición frente a esos acontecimientos por lo menos no menor a la de otras instancias pluri o multinacionales ${ }^{1}$. La tercera característica es su vigencia. El hecho de que las Cumbres se celebraran de manera anual e ininterrumpida hasta 2014, mantuvo que los asuntos tratados en ellas estuvieran siempre actualizados y fuesen pertinentes a efectos de los grandes debates globales de su tiempo. Esta condición y, principalmente, las propuestas de acción que siempre han acompañado a los pronunciamientos políticos, ha podido permitir un margen mayor a los participantes para "administrar" sus discrepancias sin llegar a convertirlas en motivo suficiente para abandonar las Cumbres.

\footnotetext{
${ }^{1}$ En efecto, un repaso de la agenda de las distintas Cumbres a lo largo de tres décadas da cuenta de la densidad de los asuntos discutidos por las y los jefes de Estado y de Gobierno. Entre otros asuntos, los debates incluyeron desde temas como el de la pobreza, la exclusión, la deuda, la salud, la educación, las migraciones y el ambiente, pasando por la igualdad de género, la lucha contra la corrupción, el narcotráfico y la delincuencia organizada transnacional, la lucha contra el terrorismo, la prevención y mitigación de desastres, la cooperación al desarrollo y los pueblos indígenas y afroamericanos, hasta la cultura e identidad iberoamericana y las relaciones UE-América Latina y el Caribe. En síntesis, las Cumbres no fueron omisas ni en cuanto a temática ni en lo que toca al contenido de referencia.
} 
Se ha mencionado que un factor clave para la supervivencia de las Cumbres Iberoamericanas es su carácter complementario con otras parecidas. Es decir, es un espacio que no compite ni busca competir — ni tampoco crear polémica - con foros ya existentes, de cuya existencia toma nota para acompañar, pero no para suplantar. Esto podría explicar que las naciones iberoamericanas no miren en las Cumbres espacios que disminuyan su capacidad de posicionamiento en ámbitos esencialmente políticos, en donde no existen márgenes para dejar "espacios vacíos".

Ello vendría acompañado de otro factor, el constituido por los programas de cooperación, que - como se indicó - han sido esenciales desde el momento mismo de la fundación de las Cumbres, tanto en lo que toca a la filosofía propiamente dicha de la comunidad iberoamericana, como a los beneficios que muchos sectores han recibido de estos. En efecto, si bien la cartera de cooperación iberoamericana es modesta comparada con la de otros organismos (como la de las Naciones Unidas o la misma OEA), es variada, abundante, innovadora $\mathrm{y}$, muy especialmente, promotora de intercambios y transferencias científicas y tecnológicas que otros no ofrecen. Contar con programas de estas características ha permitido avances notables de muchos países en áreas tales como la educación, la música, la televisión educativa, la promoción de la ciencia y la tecnología para el desarrollo, la gestión de archivos, el desarrollo de las medianas y pequeñas empresas, los bancos de leche materna y la prevención, mitigación y adaptación ante los fenómenos extremos y del cambio climático.

Finalmente, es esencial mencionar la cuestión de los liderazgos en el marco de la Secretaría General Iberoamericana (SEGIB), entidad que se puso en marcha con el Convenio de Santa Cruz de la Sierra (2003). La SEGIB es una instancia permanente que cuenta con un Convenio y con un Estatuto que le brinda amplias tareas y responsabilidades como "órgano de apoyo a la Conferencia Iberoamericana". La SEGIB es tutelada por una o un secretario general y un secretario general adjunto, que están a cargo del fortalecimiento de la comunidad iberoamericana, de su proyección internacional, del apoyo a las Cumbres, de distintas instancias iberoamericanas, y de la ejecución de sus mandatos. También deben planificar, coordinar, ejecutar, dar seguimiento y evaluar la cooperación iberoamericana, promover los vínculos entre los países miembros y presentar propuestas para fortalecer a la comunidad.

La SEGIB ha tenido dos titulares desde su fundación: don Enrique Iglesias y doña Rebeca Grynspan. Por razones de espacio resulta imposible reseñar aquí las condiciones personales de ambos. Sin embargo, 
su liderazgo internacional desde antes de convertirse en los jerarcas de la SEGIB ya era notable y se caracterizó por al menos cuatro condiciones infrecuentes en los líderes de organismos multilaterales de las últimas décadas. Su atildada honradez y capacidad intelectual; su capacidad negociadora y mediadora; su poder de convocatoria, y su autoridad moral. El hecho de que ambos, además, hayan ejercido sus cargos por periodos prolongados, les otorgó una influencia particularmente grande para lidiar con una Conferencia diversa, cuyas sensibilidades políticas e ideológicas han tenido, en otros espacios, efectos disruptores indudables.

Dos ejemplos pueden dar cuenta de la importancia de contar con liderazgos de este tipo, concertadores y flexibles. El primero, que puso a Iglesias en el centro de un conflicto verdaderamente complicado, fue el golpe de Estado del año 2009 en Honduras. El secretario general fue convocado y formó parte del grupo de mediadores que, no obstante la gravedad de lo acaecido y la imposibilidad de resolver la crisis, no fue repudiado por las partes de modo que el incidente no afectó a la Cumbre subsiguiente. El segundo ejemplo refleja la capacidad de Grynspan de mantener cohesionada a la comunidad en tiempos de COVID-19, llegando incluso a organizar una Cumbre semivirtual, con una importante participación.

\section{En conclusión}

Una de las características más notables de las Cumbres y de la comunidad iberoamericana, es su resiliencia. Las Cumbres han mantenido su periodicidad, su activismo y su presencia en el sistema internacional durante tres décadas. Y lo han hecho sin sufrir los enfrentamientos internos entre los y las jefas de Estado y de Gobierno que tanto han afectado a otras instancias similares. Aunque sea muy difícil encontrar una única causa que explique este fenómeno, es posible que resulte de la combinación de una serie de factores que incluyen su naturaleza como espacio cultural más que geopolítico, la consistencia, relevancia y vigencia de sus declaraciones, la efectividad del liderazgo de los titulares de la SEGIB y su carácter complementario, más que competitivo, con respecto a otros agrupamientos de naciones.

Sean cuales sean las razones que explican la supervivencia y vigencia de las Cumbres, su continuada existencia de tres décadas es notable. Y lo es porque si bien sus primeros años de existencia se caracterizaron por el optimismo que trajo aparejado el fin de la Guerra Fría, a partir de mediados de la última década del siglo XX y hasta la actualidad, el mundo en general, e Iberoamérica en particular, han vivido momentos de gran confusión y sobresalto. Momentos en que se han mezclado horripilantes expresiones de odio y fanatismo religiosos, con terribles confla- 
graciones bélicas, eventos climáticos extremos, profundas crisis económicas y financieras, una pandemia $y$, más recientemente, corrientes autoritarias que han revivido al nacionalismo extremo, puesto en tela de juicio la importancia del Estado de derecho y sus instituciones y, con ello, la existencia misma de la democracia, al menos de la "democracia liberal" tal y como se conoce desde finales del siglo XIX.

Para Iberoamérica la continuada existencia de su comunidad resulta importante en varios sentidos. En primer lugar, porque no existe ninguna otra asociación de naciones de carácter similar (a excepción quizá, y con sentidos comunes muy diferentes, de la mancomunidad británica), cuyo centro esté constituido por un acervo y patrimonio cultural propios, “(...) enriquecido por su diversidad nacional y regional, que comparte valores... y una concepción común del ser humano y su futuro" (Cumbre de Salvador, Bahía, 1993, núm. 36). En segundo lugar, porque la realización de las Cumbres constituye un proceso que se ha construido en torno a dos pilares: el diálogo político (especialmente en materia de implementación de políticas públicas) y la cooperación internacional. Esta última entendida como un ejercicio en donde todos los países participantes aportan recursos e intercambian conocimientos en materias muy importantes para el fortalecimiento cultural y social. La dimensión Sur-Sur de estos proyectos, poco frecuente en otros organismos, merece una referencia especial. Y, finalmente, porque abre una avenida de vínculos con otras regiones que, también integradas, constituyen una oportunidad de progreso humano y de construcción de una mejor civilización.

Hay que congratularse, pues, por las tres décadas de Cumbres Iberoamericanas, y no solo por su perdurabilidad temporal - que es, ciertamente, impresionante-, sino más bien porque representan una plataforma para propulsar el avance de un conjunto de naciones que forman una comunidad cuyo fundamento último es una “(...) identidad fundada en una concepción humanista, integral y liberadora del hombre y de la sociedad como artífices de su destino" (Lima, 2001, núm. 12). Allí, ciertamente, reside su grandeza mayor.

Luis G. Solís Rivera es director del Centro Kimberly Green para América Latina y el Caribe, Universidad Internacional de la Florida, Miami. Representante de la SEGIB para Centroamérica y Haití (2010-2012). Expresidente de la República de Costa Rica (2014-2018). 


\section{Referencias bibliográficas}

I CUMBRE IBEROAMERICANA DE JEFES DE ESTADO Y DE GOBIERNO (1991): Declaración de Guadalajara, 19 de julio de 1991. Disponible en: https://www.segib.org/?docu ment=declaracion-deguadalajara.

XI Cumbre IBEROAMERICANA DE JEFES DE ESTADO Y DE GOBIERNO (2001): Declaración de Lima, 23 y 24 de noviembre de 2001. Disponible en: https://www.segib.org/?docu ment=declaracion-de-lima.

XII Cumbre IberoamericANA DE JEFES DE ESTADO Y DE GOBIERNO (2002): Declaración de Bávaro, 15 y 16 de noviembre de 2002. Disponible en:

https://www.segib.org/wpcontent/uploads/DeclaraciondeBa varo.pdf.

XV CUMBre IBEROAMERICANA DE JEFES DE ESTADO Y DE GOBIERNO (2005): Comunicado especial de apoyo a la lucha contra el terrorismo, Salamanca, 14 y 15 de octubre. Disponible en: https://www.segib.org/?docu ment=anexo-y-comunicadosespeciales.

\section{Fundación Carolina, julio 2021}

Fundación Carolina

C/ Serrano Galvache, 26.

Torre Sur, $3^{\mathrm{a}}$ planta

28071 Madrid - España

www.fundacioncarolina.es

@ Red_Carolina

https://doi.org/10.33960/AC_22.2021

La Fundación Carolina no comparte necesariamente las opiniones manifestadas en los textos firmados por los autores y autoras que publica.

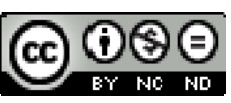

Esta obra está bajo una licencia de Creative Commons ReconocimientoNoComercial-SinObraDerivada 4.0 Internacional (CC BY-NC-ND 4.0) 